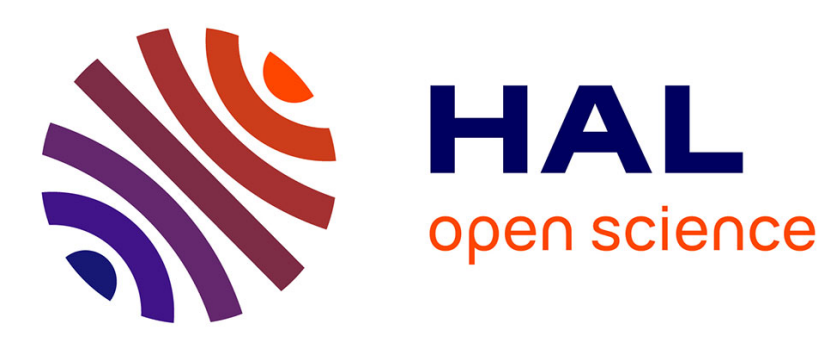

\title{
Design and Prototyping of a New Balancing Mechanism for Spatial Parallel Manipulators
}

Cédric Baradat, Vigen Arakelian, Sébastien Briot, Sylvain Guegan

\section{To cite this version:}

Cédric Baradat, Vigen Arakelian, Sébastien Briot, Sylvain Guegan. Design and Prototyping of a New Balancing Mechanism for Spatial Parallel Manipulators. Journal of Mechanical Design, 2008, 130 (7). hal-00451887

\section{HAL Id: hal-00451887 https://hal.science/hal-00451887}

Submitted on 24 Jun 2019

HAL is a multi-disciplinary open access archive for the deposit and dissemination of scientific research documents, whether they are published or not. The documents may come from teaching and research institutions in France or abroad, or from public or private research centers.
L'archive ouverte pluridisciplinaire HAL, est destinée au dépôt et à la diffusion de documents scientifiques de niveau recherche, publiés ou non, émanant des établissements d'enseignement et de recherche français ou étrangers, des laboratoires publics ou privés. 


\title{
Design and Prototyping of a New Balancing Mechanism for Spatial Parallel Manipulators
}

\author{
C. Baradat $^{* \dagger}$, V. Arakelian ${ }^{\dagger}$, S. Briot ${ }^{\dagger}$, S. Guegan ${ }^{\dagger}$ \\ * Company: «Intelligent Surgical Instruments and Systems» (ISIS) \\ 20, rue du Tour de l'Eau \\ F-38400 Saint Martin d'Hères, France \\ ${ }^{\dagger}$ Departement de Genie Mecanique et Automatique, LGCGM EA3913 \\ Institut National des Sciences Appliquees (INSA) \\ 20, Av. des Buttes de Coësmes, CS 14315, \\ F-35043 Rennes Cedex, France \\ vigen.arakelyan@insa-rennes.fr
}

\begin{abstract}
This paper proposes a new solution to the problem of torque minimization of spatial parallel manipulators. The suggested approach involves connecting a secondary mechanical system to the initial structure, which generates a vertical force applied to the manipulator platform. Two versions of the added force are considered: constant and variable. The conditions for optimization are formulated by the minimization of the root-mean-square values of the input torques. The positioning errors of the unbalanced and balanced parallel manipulators are provided. It is shown that the elastic deformations of the manipulator structure which are due to the payload, change the altitude and the inclination of the platform. A significant reduction of these errors is achieved by using the balancing mechanism. The efficiency of the suggested solution is illustrated by numerical simulations and experimental verifications. The prototype of the suggested balancing mechanism for the Delta robot is also presented.
\end{abstract}

Index terms - balancing, torque compensation, parallel mechanisms, Delta robot 


\section{Introduction}

A mechanism of parallel architecture is statically balanced if its potential energy is constant for all possible configurations ${ }^{1}$. This means that the mechanism is statically stable for any configuration, i.e. zero actuator torques due to the static loads are required. For static balancing of robot mechanisms, different approaches and solutions have been developed and documented [3-41]. The balancing schemes for robotic systems can be systematized by means of balancing (table 1): counterweight (group A), spring (group B), pneumatic or hydraulic cylinder, electromagnetic device, etc. (group C). Each group can be presented by the following subgroups:

A1. Balancing by counterweights mounted on the links of the initial system [3-6]. Such balancing is very simple to realize. However, it leads to the important increase of the moving masses of the manipulator, and as a result, its inertia.

A2. Balancing by counterweights mounted on the auxiliary linkage connected with the initial system [7-10]. Articulated dyads or pantograph mechanism are used as an auxiliary linkage.

B1. Balancing by springs jointed directly with manipulator links [11-14]

B2. Balancing by using a cable and pulley arrangement [15-18]. Such an approach allows zero free length springs to be used, which is more favorable for realization of complete balancing.

Balancing by using an auxiliary mechanism can be presented in the following manner:

B3.1. Balancing by using an auxiliary linkage [19-29].

B3.2. Balancing by using a cam mechanism [30-33].

B3.3. Balancing by using gear train [34-37].

\footnotetext{
${ }^{1}$ It should be noted that, in the balancing of high-speed mechanisms, the term «static balancing» refers to shaking force cancellation or minimization [1,2]. With regard to the «static balancing» in robotics, this term
} 
Table 1. Balancing schemes for robotic systems

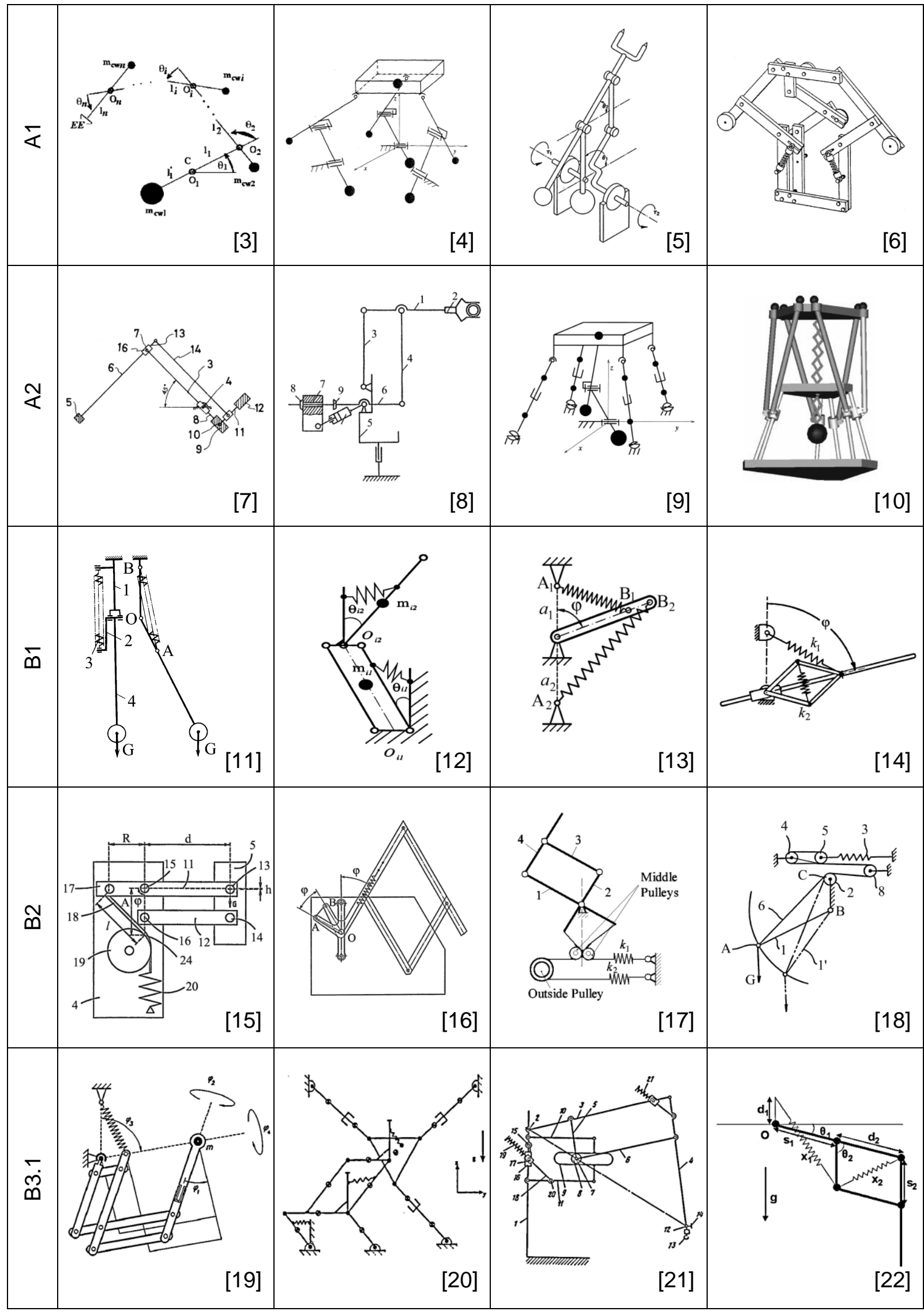

differs from the first definition, because in this case, the aim of the balancing is the minimization or cancellation of input torques of mechanical system by means of gravitational force balancing. 


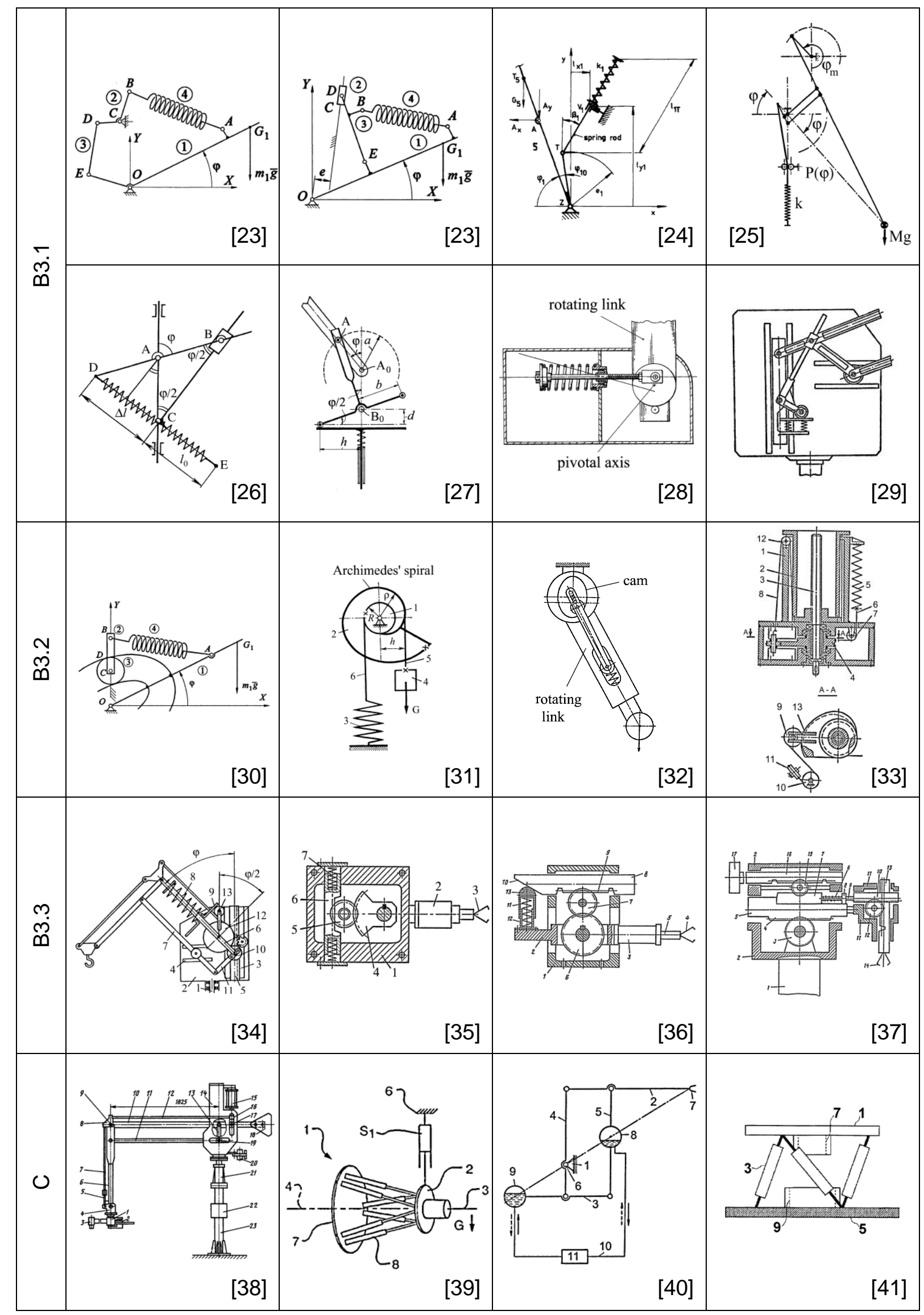


C. Balancing by using pneumatic or hydraulic cylinders, which are connected with manipulator links [38] or directly with the moving platform [39]. There is a balancing approach based on counterweights, which are fluid reservoirs. Continuous balancing is achieved by the pumping of the fluid from the first reservoir-counterweight to the second [40]. Electromagnetic effects were also used for balancing [41].

The literature review showed that many balancing methods are applicable for planar parallel manipulators. However the balancing of spatial parallel architectures is a complicated problem because it can be achieved either by unavoidable increase of the total mass of moving links or by a considerably complicated design of the initial parallel mechanism. Let us consider this problem for the Delta robot.

The Delta robot [42] was developed for high-speed manipulation and it is well known in the electronics, food and pharmaceutical sectors as a reliable system with fast execution of light-duty tasks. However, in recent years, more attention has been paid to the increasing number of possible industrial applications, such as manipulation of medical devices (Fig. 1).

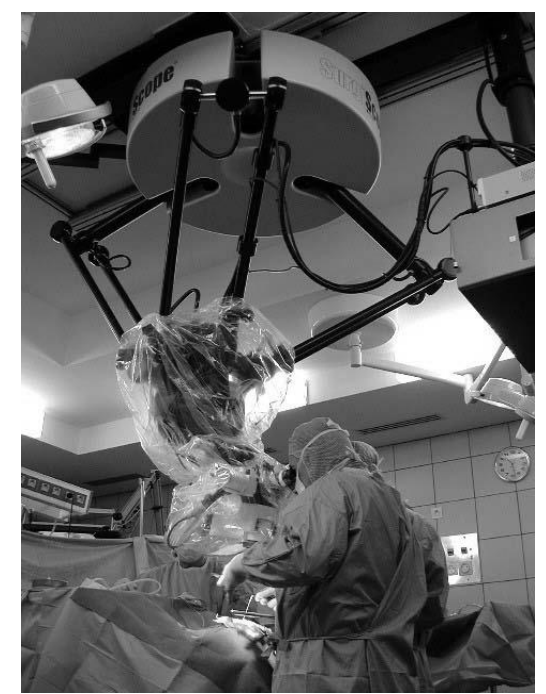

Fig. 1. A Delta robot used in the SurgiScope ${ }^{\circledR}$, a robotized navigation tool-holder designed for neurosurgery and developed by the ISIS $^{2}$ company.

\footnotetext{
${ }^{2}$ ISIS : Intelligent Surgical Instruments \& Systems (http://www.isis-robotics.com).
} 


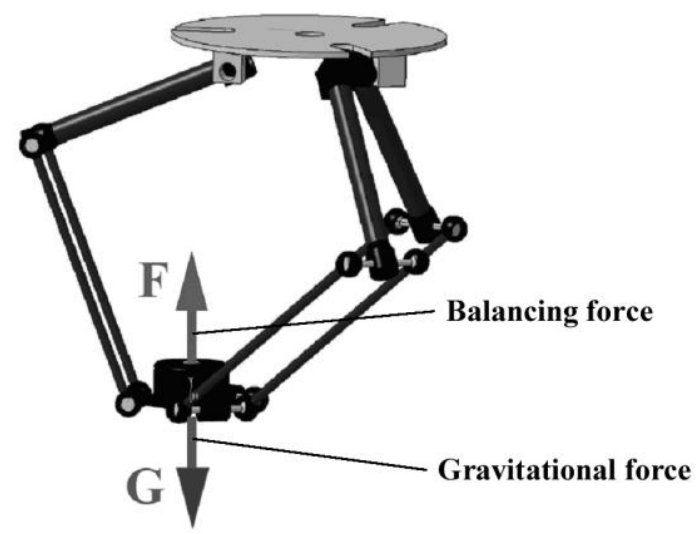

Fig. 2. Principle of balancing.

In this case, the displacement speed of the platform is not essential because there is no need for productivity acceleration. However, as a result of the increased mass of the platform (about $70 \mathrm{~kg}$ ), the input torques became important. Thus it became evident that the platform's mass must be balanced. In this case, the traditional approaches with counterweights and springs mounted on the moving links are not applicable. The Delta robot has a complex structure and after such balancing it becomes either very heavy or a complicated assembly with several complementary articulated dyads. That is why another means for the solution of this problem is proposed. It consists in the addition of a secondary mechanism between the manipulator base and moving platform. This mechanism can create a supplementary vertical force $F$ on the platform to balance the gravitational forces of the robot (Fig. 2).

In this context, a new balancing mechanism for the minimization of the input torque of the spatial parallel manipulators with high weight-carrying capacity is developed.

\section{Description of the balancing mechanism}

The suggested balancing system includes (Fig. 3) a pantograph mechanism mounted on the rotating stand connected with the base. 


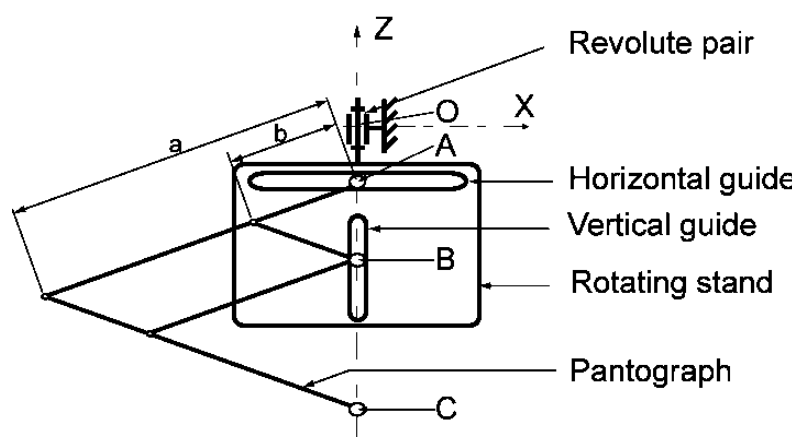

Fig. 3. Simplified scheme of the balancing mechanism.

The input points $A$ and $B$ of the pantograph are located in the horizontal and vertical guides of the rotating stand. So the suggested system has three degrees of freedom: a rotation of the stand about the vertical axis and two translations along the guides. This allows the suggested system to be passive in relation to the Delta robot when the point $C$ is connected with the platform.

Point $B$ is also connected with an actuator which produces a vertical force. This vertical force $F_{B}$ is used for the balancing of the gravitational forces of the spatial parallel robot. It is obvious that the determination of the balancing force $F_{B}=k F$ takes into account the magnification factor of the pantograph $(k=A C / A B=a / b)$.

Thus the position of point $C$ is represented by vector $\mathbf{P}=[x, y, z]^{T}$ and the passive motions of the pantograph are represented by $\mathbf{q}=[r, \theta, Z]^{T}$. The kinematic relations between $\mathbf{P}$ and $\mathbf{q}$ are the following: $x=(1-k) r \cos \theta, y=(1-k) r \sin \theta$ and $z=k Z$. Differentiating these equations with respect to time, one obtains:

$$
\dot{\mathbf{q}}=\mathbf{J}^{-1} \dot{\mathbf{P}}
$$

where

$$
\begin{aligned}
& \dot{\mathbf{P}}=\left[\begin{array}{lll}
\dot{x} & \dot{y} & \dot{z}
\end{array}\right]^{T} \\
& \dot{\mathbf{q}}=\left[\begin{array}{lll}
\dot{r} & \dot{\theta} & \dot{Z}
\end{array}\right]^{T}
\end{aligned}
$$




$$
\mathbf{J}=\left[\begin{array}{ccc}
(1-k) \cos \theta & (k-1) r \sin \theta & 0 \\
(1-k) \sin \theta & (1-k) r \cos \theta & 0 \\
0 & 0 & k
\end{array}\right]
$$

It is obvious that the added balancing system cannot follow all trajectories of the parallel robot. For example, if the given trajectory of the parallel robot is composed from two mutually perpendicular straight lines, which are intersected at the point of $x=y=0$, the balancing mechanism cannot execute a continuous motion. In this case, it is necessary to orientate the plane of the pantograph mechanism relative to the $\mathbf{Z}$ axis. Thus, it is evident that the balancing mechanism must be equipped with a complementary rotating actuator for its orientation in the case of singular trajectories. This complementary actuator may be in operation only for special cases.

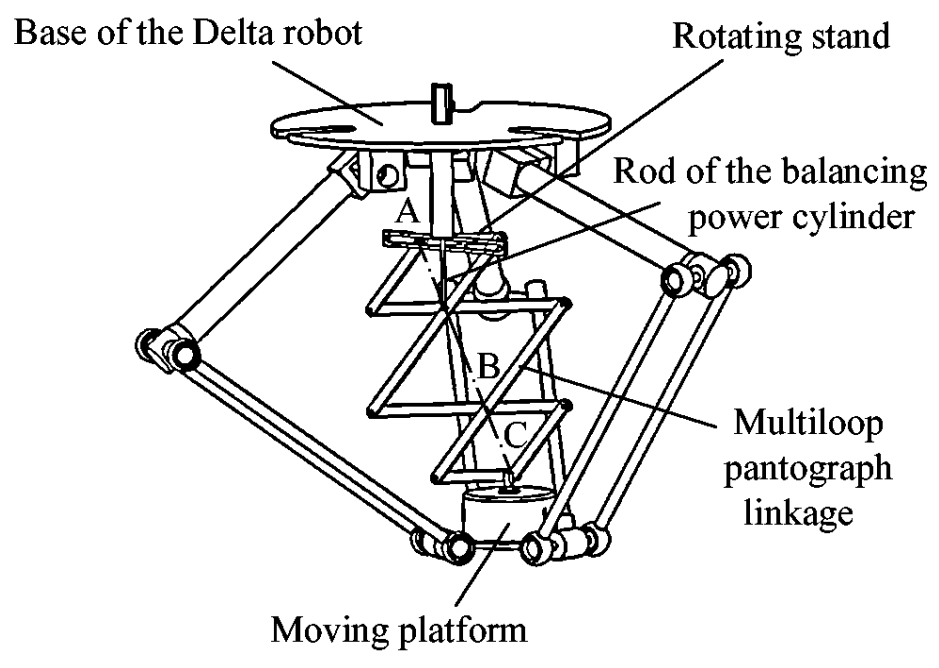

Fig. 4. Delta robot with the balancing mechanism.

Fig. 4 shows the balancing mechanism, which is implemented in the structure of the Delta robot. Multiloop pantograph linkage with several link lengths allows the reduction of the overall size of the balancing mechanism. The size of the pantograph links must be chosen in such a manner that they should not collide with the legs of the Delta robot. 
However, it is necessary to note that the suggested balancing mechanism is applicable to many spatial parallel robots from 3 to 6 degrees of freedom.

Fig. 5 shows an example of such an application for the Gough-Stewart platform with the implemented balancing system.

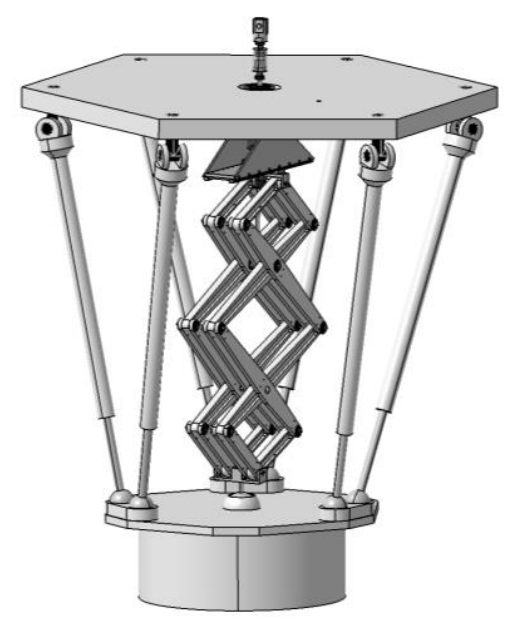

Fig. 5. Stewart platform with implemented balancing system.

In the proposed design of the Gough-Stewart platform the payload is balanced by the suggested mechanism. So the platform becomes a weightless link and it can be displaced and oriented by low-power linear actuators.

In the following section we consider the balancing of the Delta robot by means of the proposed mechanism and we discuss the minimization of the input torques by a constant or a variable force.

\section{Minimization of the torque by a constant force applied to the robot platform}

Let us examine two cases: minimization of the torques due to the static loads, i.e. weights of the moving links, and dynamic forces, i.e. inertia forces. 


\subsection{Minimization of the torques due to static loads (gravitational forces).}

The input torque of the $n^{\text {th }}$ actuator can be expressed as:

$$
M_{n}^{s t}=M_{1 n}^{s t}+M_{2 n}^{s t}+M_{3 n}^{s t}+M_{4 n}^{s t}
$$

where $M_{1 n}^{s t}$ is the torque due to the gravitational forces of the arms (see Fig. 6), $M_{2 n}^{s t}$ is the torque due to the parallelograms, $M_{3 n}^{s t}$ is the torque due to the joints on points $B_{i}, M_{4 n}^{s t}$ is the torque due to the gravity forces of the platform and medical device. For $i, n=1,2,3$ and for $j$ $=1,2,3 \mathbf{M}_{j n}^{s t}$ is equal to:

$$
\mathbf{M}_{j n}^{s t}(x, y, z)=\left(\sum_{i=1}^{3} \mathbf{J}_{j i}^{T}(x, y, z) \cdot \mathbf{G}_{j i}\right) \|_{p}
$$

and for $n=1,2,3$ and $j=4, \mathbf{M}_{4 n}^{s t}$ is equal to:

$$
\mathbf{M}_{4 p}^{s t}(x, y, z)=\left.\left(\mathbf{J}^{T}(x, y, z) \cdot \mathbf{G}\right)\right|_{p}
$$

where $\mathbf{J}_{1 i}$ is the Jacobian matrix between the point $P_{1 i}$ and the actuated variables $\theta_{n}, \mathbf{J}_{2 i}$ is the Jacobian matrix between the point $P_{2 i}$ and the actuated variables $\theta_{n}, \mathbf{J}_{3 i}$ is the Jacobian matrix between the point $B_{i}$ and the actuated variables $\theta_{n}, \mathbf{J}$ is the general Jacobian matrix of the robot, between the point $P$ and the actuated variables $\theta_{n}$ for $i, n=1,2,3$, and $\mathbf{G}$ and $\mathbf{G}_{j i}$ are the gravity forces (Fig. 6). The matrix $\mathbf{J}_{j i}(j=1,2,3)$ can be written as:

$$
\begin{aligned}
& \mathbf{J}_{1 i}=\left[\frac{\partial \mathbf{O P}_{1 i}}{\partial \theta_{n}}\right] ; \quad \mathbf{J}_{2 i}=\left[\frac{\partial \mathbf{O} \mathbf{P}_{2 i}}{\partial \theta_{n}}\right] ; \\
& \mathbf{J}_{3 i}=\left[\frac{\partial \mathbf{O B}}{\partial \theta_{n}}\right] \quad ; \quad \mathbf{J}=\left[\frac{\partial \mathbf{O P}}{\partial \theta_{n}}\right] .
\end{aligned}
$$

Fig. 7 shows the workspace with the torque of the actuator 1 for each position of the workspace of the Delta robot. It should be noted that, as the DELTA robot which we are studying is symmetrical, the values of the input torques for the actuators are also symmetrical but they are situated in different zones (rotations of $\pm 120^{\circ}$ ). The values of the input torque are differentiated by the contrast intensity. 


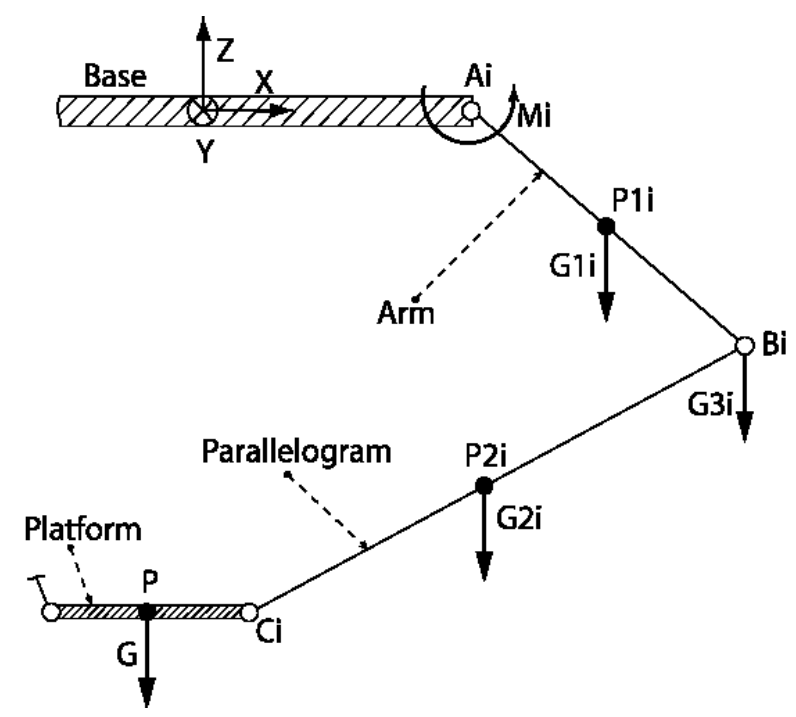

Fig. 6. Gravitational forces for the leg $i$.

The three input torques can be presented by the following expression:

$$
\left\{\begin{array}{l}
M_{1 b a l}^{s t} \\
M_{2 b a l}^{s t} \\
M_{3 b a l}^{s t}
\end{array}\right\}=\left\{\begin{array}{l}
M_{1}^{s t} \\
M_{2}^{s t} \\
M_{3}^{s t}
\end{array}\right\}+\mathbf{J}^{T}\left\{\begin{array}{l}
0 \\
0 \\
F
\end{array}\right\}
$$

where $M_{i b a l}^{s t}$ is the optimized torque of actuator $i(i=1,2,3)$.

The condition for the minimization of the root-mean-square (RMS) value of the torques can be expressed as:

$$
\sqrt{\frac{\sum_{p=1}^{N}\left(\sum_{i=1}^{3}\left(M_{i}^{s t}\left(x_{p}, y_{p}, z_{p}\right)+J_{(3 i)}\left(x_{p}, y_{p}, z_{p}\right) F\right)^{2}\right)}{N}} \rightarrow \min _{F}
$$

where $M_{i}^{s t}$ is the initial torque of the actuator $i, N$ is the number of calculated positions of the robot, $J_{(3 i)}$ is the $i^{\text {th }}$ column of the third line of the matrix $\mathbf{J}, i=1,2,3$ is the number of the actuator and $x_{p}, y_{p}, z_{p}$ are the coordinates of the $p^{\text {th }}$ calculated position of the workspace.

For the minimization of the RMS value of the torques, it is necessary to minimize the sum:

$$
\Delta=\sum_{k=1}^{N}\left(\sum_{i=1}^{3}\left(M_{i}^{s t}\left(x_{p}, y_{p}, z_{p}\right)+J_{(3 i)}\left(x_{p}, y_{p}, z_{p}\right) F\right)^{2}\right)
$$


For this purpose, we shall achieve the condition: $\frac{\partial \Delta}{\partial F}=0$, from which we determine the force:

$$
F=-\frac{\sum_{k=1}^{N}\left(\sum_{i=1}^{3} J_{(3 i)}\left(x_{p}, y_{p}, z_{p}\right) M_{i}\left(x_{p}, y_{p}, z_{p}\right)\right)}{\sum_{k=1}^{N}\left(\sum_{i=1}^{3} J_{(3 i)}^{2}\left(x_{p}, y_{p}, z_{p}\right)\right)}
$$

Numerical example. For the Delta robot of the SurgiScope ${ }^{\circledR}$, the parameters are the following (see Fig. 6):

- $\quad l_{A i B i}=0,75 \mathrm{~m}$;

- $\quad l_{B i C i}=0,95 \mathrm{~m} ;$

- $\quad m_{1 i}=2,3 \mathrm{~kg}$ (mass of $i^{\text {th }}$ arm with center $P_{1 i}$ );

- $\quad m_{2 i}=5,2 \mathrm{~kg}$ (mass of $i^{\text {th }}$ parallelogram with center $P_{2 i}$ );

- $\quad m_{3 i}=3,1 \mathrm{~kg}$ (mass of the joint at point $B_{i}$ );

- $\quad m=79 \mathrm{~kg}$ (mass of the platform, joints and medical device, with center in the point $P$ );

- $\quad l_{A i P 1 i}=l_{A i B i} / 2=0,375 \mathrm{~m}$;

- $\quad l_{B i P 2 i}=l_{B i C i} / 2=0,475 \mathrm{~m}$.

Thus the value of the added force for the given parameters is $F=931 \mathrm{~N}$.

Fig. 7 shows the variations of the input torques for unbalanced and balanced Delta robot. Thus, the reduction of the RMS value of the input torque is $99.5 \%$. The reduction of the maximum value of the torque is $92 \%$.

The purpose of this study is to develop a reliable mechanism for gravitational force balancing of spatial parallel manipulators. Moreover, it is also tempting to consider the minimization of the torques due to the dynamic loads, i.e. inertia forces. 

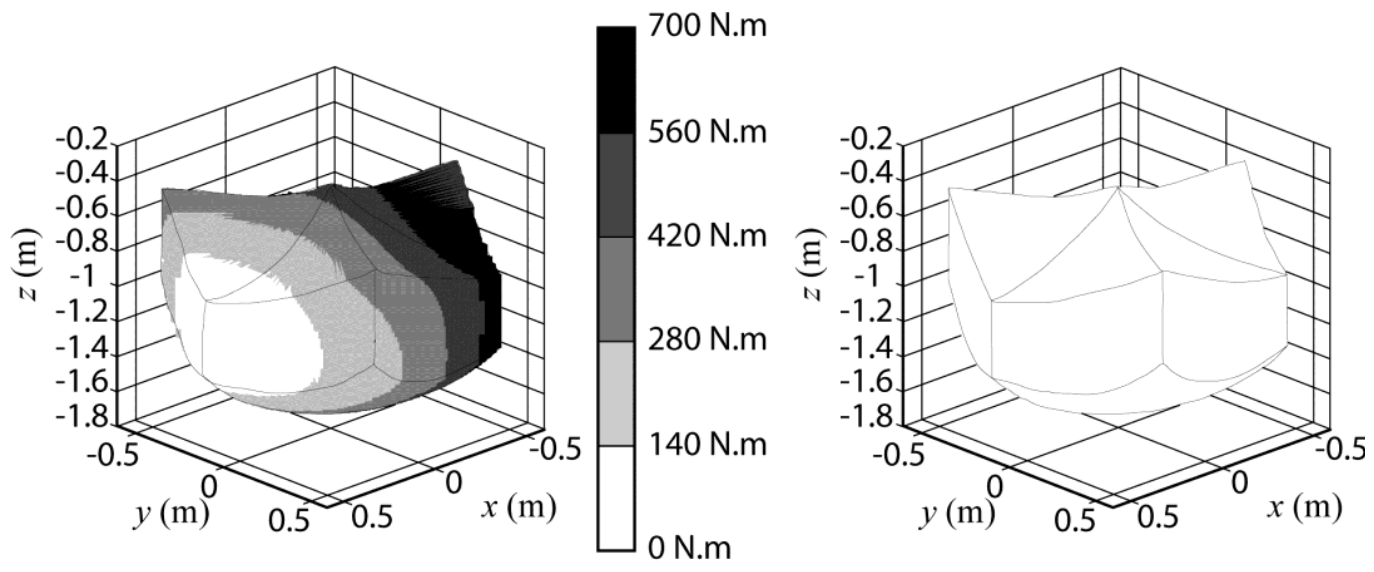

Fig. 7. Input torque 1 for unbalanced (left) and balanced (right) Delta robot.

\subsection{Minimization of the torques due to the dynamic loads (inertia and gravitational forces).}

The input torque of the $i^{\text {th }}$ actuator can be expressed as [43]:

$$
M_{i}^{d y n}=\frac{d}{d t}\left(\frac{\partial L}{\partial \dot{\alpha}_{i}}\right)-\frac{\partial L}{\partial \alpha_{i}}-\lambda_{i} A_{i, i+3}, \quad i=1,2,3 .
$$

With the added force $F$, Eq. (13) can be written as:

$$
M_{i b a l}^{d y n}=M_{i}^{d y n}+B_{i 3} A_{i, i+3} F
$$

where $\left[B_{i j}\right]$ is the inverse matrix of matrix $\mathbf{A}[43]$ composed by the first three columns only.

We would like to point out that, in the case of the dynamic study, the input torques depend on the velocity and acceleration of the platform displacement and it is impossible to realize an optimization for the whole workspace of the robot (as it was for the static load minimization). Thus we must define a trajectory in which the input torques will be minimized. The selected trajectory is presented in Fig. 8. The kinematic characteristics of the examined motion are given by the maximum values of the acceleration and velocity and presented in table 2 (factors «a» and «v»).

The condition for the minimization of the RMS value of the torques can be expressed as: 


$$
\sqrt{\sum_{p=1}^{N}\left(\sum_{i=1}^{3}\left(M_{i}^{d y n}+B_{i 3} A_{i, i+3} F\right)^{2}\right) / N} \rightarrow \min _{F}
$$

where $M_{i}^{d y n}$ is the initial torque of the actuator $i, N$ is the number of calculated positions of the robot, $i=1,2,3$ is the number of the actuator.

For the minimization of the RMS value of the torques, it is necessary to minimize the sum:

$$
\Delta=\sum_{p=1}^{N}\left(\sum_{i=1}^{3}\left(M_{i}^{d y n}+B_{i 3} A_{i, i+3} F\right)^{2}\right) \rightarrow \min _{F}
$$

For this purpose, we shall achieve the condition: $\frac{\partial \Delta}{\partial F}=0$, from which we determine the force:

$$
F=-\frac{\sum_{p=1}^{N}\left(\sum_{i=1}^{3} B_{i 3} A_{i, i+3} M_{i}^{d y n}\right)}{\sum_{p=1}^{N}\left(\sum_{i=1}^{3}\left(B_{i 3} A_{i, i+3}\right)^{2}\right)}
$$

For the examined trajectory with $\mathrm{a}=1,05 \mathrm{~m} / \mathrm{s}^{2}$ and $\mathrm{v}=0,79 \mathrm{~m} / \mathrm{s}$, we determine the external force: $F=934$ N.

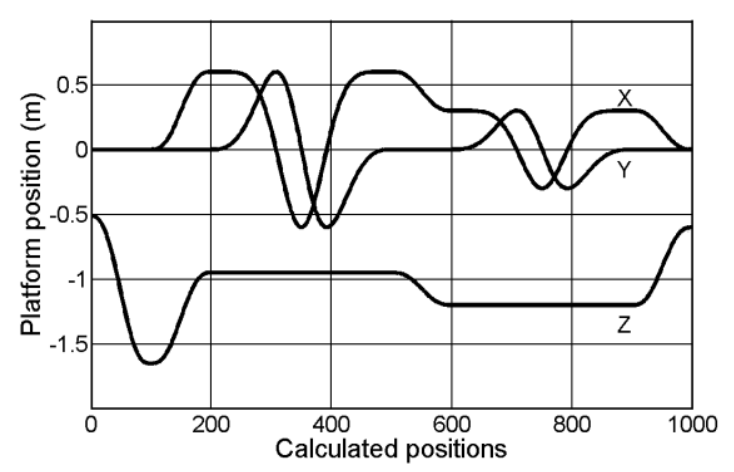

Fig. 8. The output parameters for the selected trajectory. 
Table 2. Input torques for unbalanced and balanced robots

\begin{tabular}{|c|c|c|c|c|}
\hline $\begin{array}{c}\text { Maximum values of } \\
\text { the acceleration and } \\
\text { velocity }\end{array}$ & \multicolumn{2}{|l|}{ Maximum value of the input torque 1 (N.m) } & Balancing force \\
\cline { 2 - 5 } & unbalanced & balanced & Gain \\
\hline $\begin{array}{c}\mathrm{a}=0.1 \mathrm{~m} / \mathrm{s}^{2} \\
\mathrm{v}=0.26 \mathrm{~m} / \mathrm{s}\end{array}$ & 645 & 57 & 956 & $91 \%$ \\
\hline $\mathrm{a}=1.05 \mathrm{~m} / \mathrm{s}^{2}$ & 652 & 110 & 897 & $83 \%$ \\
$\mathrm{v}=0.79 \mathrm{~m} / \mathrm{s}$ & 677 & 326 & 779 & $49 \%$ \\
\hline $\mathrm{a}=4.13 \mathrm{~m} / \mathrm{s}^{2}$ & & & & \\
$\mathrm{v}=1.57 \mathrm{~m} / \mathrm{s}$ & & & & \\
\hline
\end{tabular}

Fig. 9 shows the variations of the input torque 1 for the unbalanced and balanced Delta robots (for $\mathrm{a}=1.05 \mathrm{~m} / \mathrm{s}^{2}, \mathrm{v}=0.79 \mathrm{~m} / \mathrm{s}$, when the reduction of the input torques is $83 \%$ ).

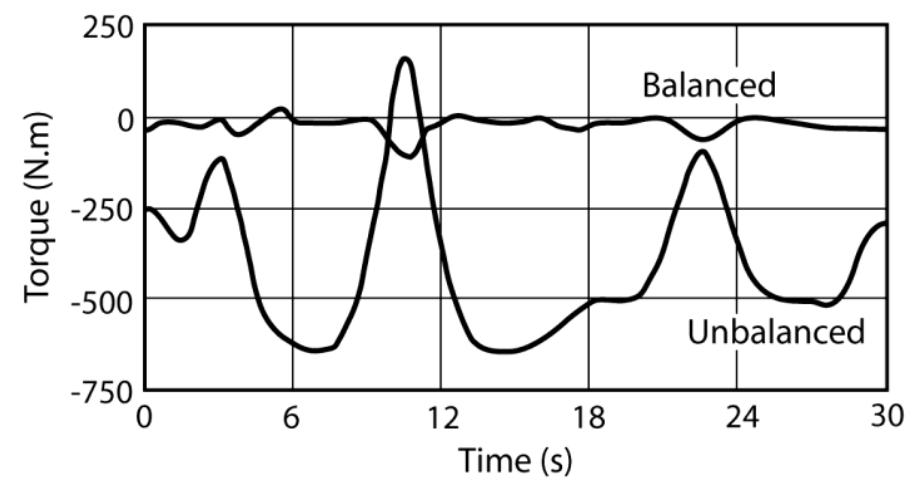

Fig. 9. Input torque 1 for unbalanced and balanced Delta robot.

\section{Minimization of the input torques by a variable force applied to the platform of the} robot

This section also contains two cases: minimization of the input torques due to the static and dynamic forces. 


\subsection{Minimization of the torques due to the static loads (gravitational forces).}

The relationship between the actuator input torques and the resultant force can be written as:

$$
\mathbf{F}^{r e s}=\mathbf{J}^{-T} \mathbf{M}^{s t}
$$

where $\mathbf{M}^{s t}=\left\{\begin{array}{lll}M_{1}^{s t} & M_{2}^{s t} & M_{3}^{s t}\end{array}\right\}^{T}$.

This variable force has three components along the $\mathbf{X}, \mathbf{Y}$ and $\mathbf{Z}$ axes. For minimization of the input torques we use the component of $\mathbf{F}^{\text {res }}$ along the $\mathbf{Z}$ axis, which is similar to the added force $F$.

It should be noted that the difference in the minimized torques between the two examined cases (with constant and variable forces) is very small (about 1\%). Thus, for the minimization of the static loads it is better to use constant force. The constant force is easier to create than the variable force.

\subsection{Minimization of the torques due to the dynamic loads (inertia and gravitational} forces).

The expressions for the input torques are similar to those in the previous case:

$$
M_{i b a l}^{d y n}=M_{i}^{d y n}+B_{i 3} A_{i, i+3} F
$$

The condition for the minimization of the torques at the $p^{\text {th }}$ calculated position is formulated as:

$$
\Delta_{p}=\sum_{i=1}^{3}\left(M_{i}^{d y n}+B_{i 3} A_{i, i+3} F\right)^{2} \rightarrow \min _{F_{p}}, p=1, \ldots, N
$$

where $M_{i}^{d y n}$ is the initial torque of the actuator $i, N$ is the number of calculated positions of the simulation, $i=1,2,3$ is the number of the actuator.

From condition $\frac{\partial \Delta_{p}}{\partial F_{p}}=0$, we determine the external force for each position of the trajectory: 


$$
F_{p}=-\frac{\sum_{i=1}^{3}\left(B_{i 3} A_{i, i+3} M_{i}^{d y n}\right)}{\sum_{i=1}^{3}\left(B_{i 3} A_{i, i+3}\right)^{2}}, \quad p=1, \ldots, N
$$

Table 3 presents the maximum values of the torques for three examined cases. It should be noted that in this case also, the increase in the velocity and acceleration leads to the reduction of the efficiency of the minimization.

We would like to draw attention to the fact that the added force $F$ is always vertical and cannot compensate for all effects of the inertia forces along the $\mathbf{X}$ and $\mathbf{Y}$ axes.

Table 3. Input torques for unbalanced and balanced robots

\begin{tabular}{|c|c|c|c|}
\hline \multirow{2}{*}{$\begin{array}{l}\text { Maximum values of the acceleration } \\
\text { and velocity }\end{array}$} & \multicolumn{2}{|c|}{ Maximum value input torque 1 (N.m) } & \multirow{2}{*}{ Gain } \\
\hline & Unbalanced & Balanced & \\
\hline $\begin{aligned} \mathrm{a} & =0.1 \mathrm{~m} / \mathrm{s}^{2} \\
\mathrm{v} & =0.26 \mathrm{~m} / \mathrm{s}\end{aligned}$ & 645 & 40 & $94 \%$ \\
\hline $\begin{array}{l}\mathrm{a}=1.05 \mathrm{~m} / \mathrm{s}^{2} \\
\mathrm{v}=0.79 \mathrm{~m} / \mathrm{s}\end{array}$ & 652 & 96 & $85 \%$ \\
\hline $\begin{array}{l}\mathrm{a}=4.13 \mathrm{~m} / \mathrm{s}^{2} \\
\mathrm{v}=1.57 \mathrm{~m} / \mathrm{s}\end{array}$ & 677 & 262 & $60 \%$ \\
\hline
\end{tabular}

Fig. 10 shows the variations of the input torques for the initial and optimized cases (for a = $1.05 \mathrm{~m} / \mathrm{s}^{2}, \mathrm{v}=0.79 \mathrm{~m} / \mathrm{s}$, when the reduction of the input torques is $85 \%$ ). 


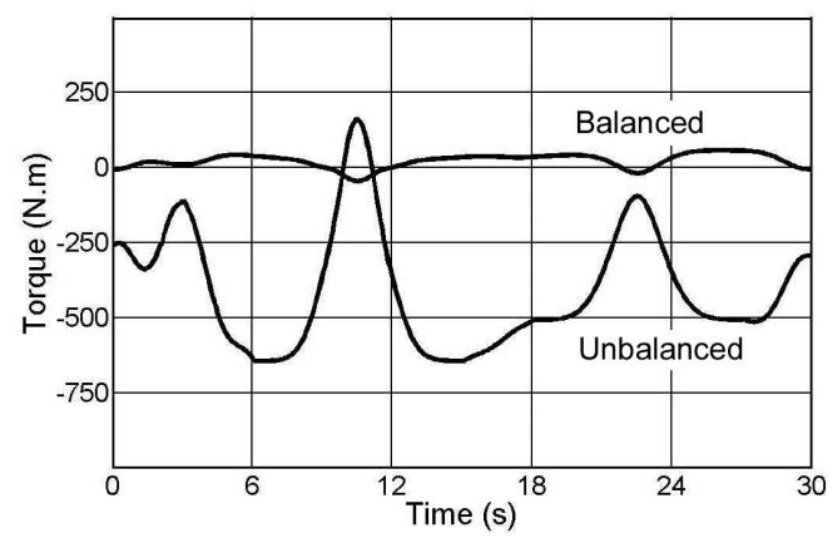

Fig. 10. Input torque 1 for unbalanced and balanced Delta robot.

It should be noted that these simulations showed that the minimization of the input torques achieved by using a variable force is not very efficient. The difference between two examined cases with constant and variable forces is very small. Taking into account the difficulty involved in the practical realization of the variable force, we can conclude that for the suggested balancing mechanism it is enough to use the constant force.

\section{Increase in the positioning accuracy of spatial parallel manipulators balanced by the suggested mechanism}

It should be noted that most research papers devoted to the study of parallel manipulators deal with the mechanical structures with rigid links. So in this case, the position of the platform is considered to be perfectly parallel to the base and its coordinates are determined from the nominal values of the link lengths. But in reality, the errors due to the elastic deformations of the mechanical structure of the manipulator change the position and orientation of the platform. Our observation showed that the increase in the platform mass leads to increases in these errors. In this section, it will be shown that the suggested balancing mechanism has a positive influence on the improvement of the positioning accuracy of the parallel robot. 
Static rigidity of the Delta robot is defined as the $6 \times 6$ symmetrical matrix $\mathbf{K}$ that maps generalized infinitesimal displacements $\Delta \mathbf{X}=\left[\begin{array}{llllll}\delta x & \delta y & \delta z & \delta \phi_{x} & \delta \phi_{y} & \delta \phi_{z}\end{array}\right]^{T}$ of the platform to generalized external loads $\mathbf{F}=\left[\begin{array}{llllll}F_{x} & F_{y} & F_{z} & M_{x} & M_{y} & M_{z}\end{array}\right]^{T}$.

Thus, we have

$$
\mathbf{F}=\mathbf{K} \Delta \mathbf{X}
$$

Table 4. Link parameters

\begin{tabular}{|c|c|c|c|c|c|}
\hline \multirow{2}{*}{ Link } & Cross-section & Quadratic & Quadratic & Elastic & Poisson \\
& area $\left(\mathrm{m}^{2}\right)$ & moment & moment & modulus $(E)$ & coefficient \\
& about $\mathbf{y}\left(\mathrm{m}^{4}\right)$ & about $\mathbf{z}\left(\mathrm{m}^{4}\right)$ & $(\mathrm{GPa})$ & $(\mathrm{v})$ \\
\hline Links $A_{i} B_{i}$ & $1.124 \cdot 10^{-3}$ & $7.913 \cdot 10^{-7}$ & $7.913 \cdot 10^{-7}$ & 70 & 0.346 \\
\hline Parallelogram & $1.773 \cdot 10^{-4}$ & $2.13 \cdot 10^{-8}$ & $2.13 \cdot 10^{-8}$ & 70 & 0.346 \\
\hline links & & & & & \\
\hline
\end{tabular}

With the link parameters given in table 4 and the payload equal to $70 \mathrm{~kg}$, the positioning errors caused by the elastic deformation of the robot structure is represented in Fig. 11 (dark gray). When the balancing force $\left(F_{\text {bal }}=931 N\right)$ is applied on the platform, the relationship (23) can be rewritten as:

$$
\mathbf{F}_{\text {bal }}+\mathbf{F}=\mathbf{K} \Delta \mathbf{X}_{\text {bal }}
$$

where $\mathbf{F}_{\text {bal }}=\left[0,0, F_{\text {bal }}, 0,0,0\right]^{T}$.

Fig. 11 shows the positioning errors caused by the elastic deformation of the robot structure with balancing mechanism (light gray). 
Table 5 shows a comparative analysis of the maximum values of the positioning errors along the corresponding axis for the two cases. The reduction in the positioning and orientation errors is significant (from $86.8 \%$ to $97.5 \%$ ).

Table 5. Maximal absolute positioning and orientation errors for unbalanced and balanced robots

\begin{tabular}{|c|c|c|c|}
\hline \multirow{2}{*}{} & \multicolumn{2}{|c|}{ Maximal absolute positioning errors } & \multirow{2}{*}{ Gain } \\
\cline { 2 - 4 } & Unbalanced robot & Balanced robot & \\
\cline { 2 - 4 } & $\delta x=0.92 \mathrm{~mm}$ & $\delta x_{\text {bal }}=0.109 \mathrm{~mm}$ & $88.2 \%$ \\
\cline { 2 - 4 }$\left(F_{\text {bal }}=931 N\right)$ & $\delta y=0.923 \mathrm{~mm}$ & $\delta y_{\text {bal }}=0.107 \mathrm{~mm}$ & $88.4 \%$ \\
\cline { 2 - 4 } & $\delta z=2.636 \mathrm{~mm}$ & $\delta z_{\text {bal }}=0.065 \mathrm{~mm}$ & $97.5 \%$ \\
\cline { 2 - 4 } & $\delta \phi_{x}=4.35 \cdot 10^{-3}$ radian & $\delta \phi_{x \text { bal }}=0.41 \cdot 10^{-3}$ radian & $90.6 \%$ \\
\cline { 2 - 4 } & $\delta \phi_{y}=3.37 \cdot 10^{-3}$ radian & $\delta \phi_{y_{\text {bal }}}=0.31 \cdot 10^{-3}$ radian & $90.8 \%$ \\
\hline & $\delta \phi_{z}=0.13 \cdot 10^{-3}$ radian & $\delta \phi_{z \text { bal }}=0.02 \cdot 10^{-3}$ radian & $86.8 \%$ \\
\hline
\end{tabular}

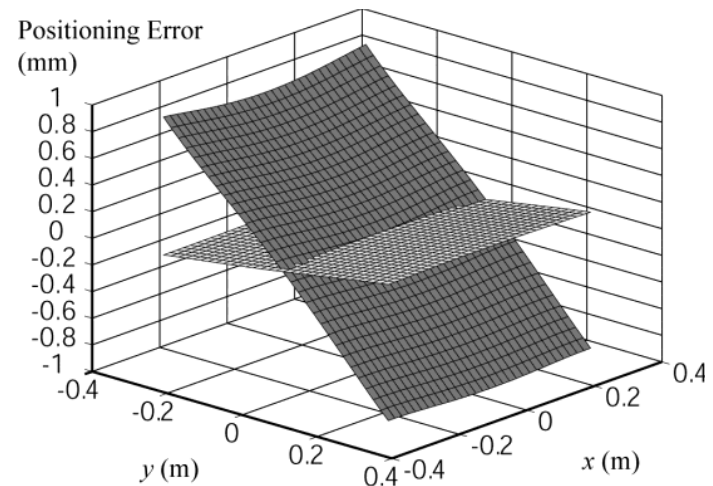

(a) Errors caused by the linear displacements of the platform along the $\mathbf{X}$ axis.

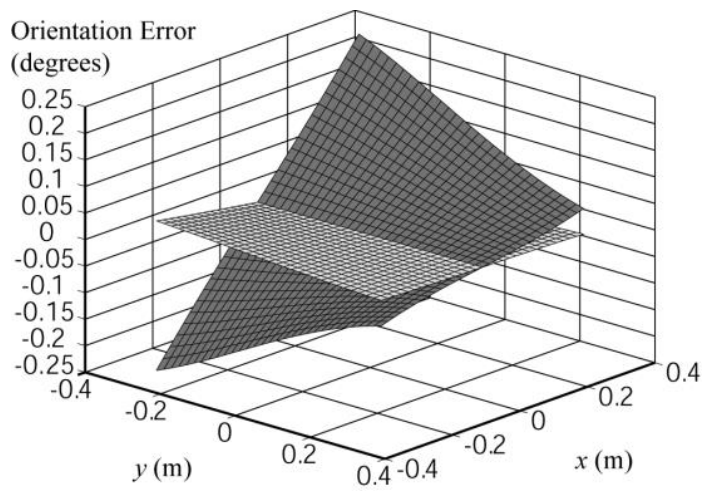

(d) Errors caused by the rotation of the platform about the $\mathbf{X}$ axis. 


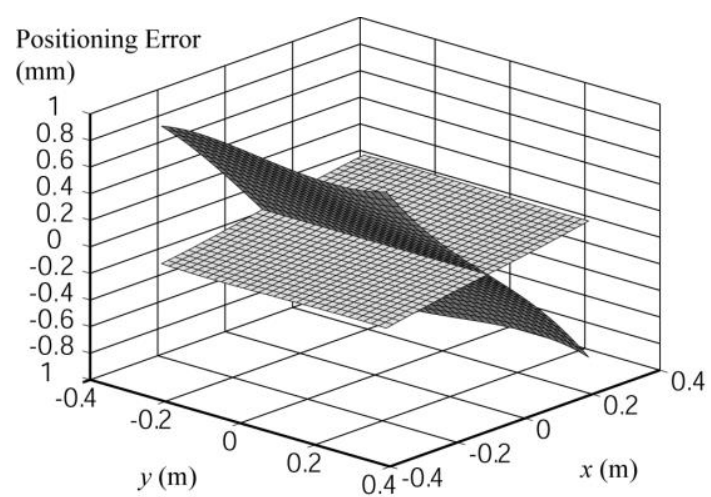

(b) Errors caused by the linear displacements

of the platform along the $\mathbf{Y}$ axis

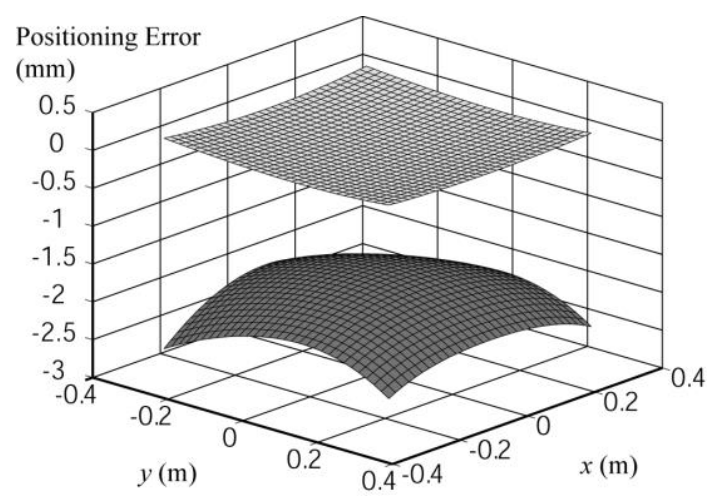

(c) Errors caused by the linear displacements

of the platform along the $\mathbf{Z}$ axis

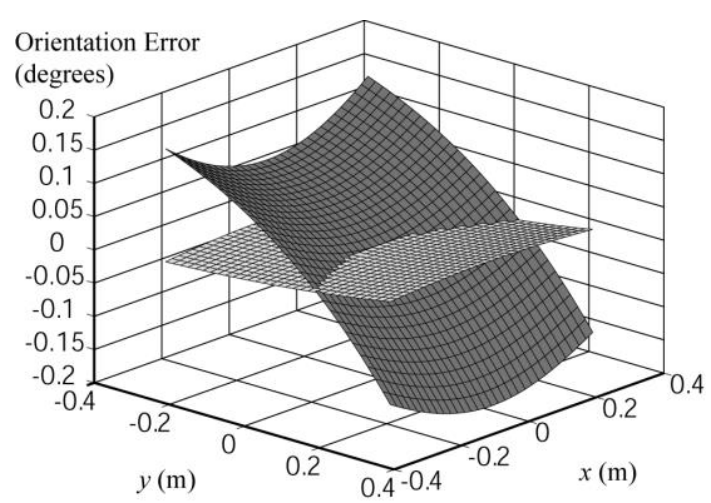

(e) Errors caused by the rotation of the

platform about the $\mathbf{Y}$ axis.

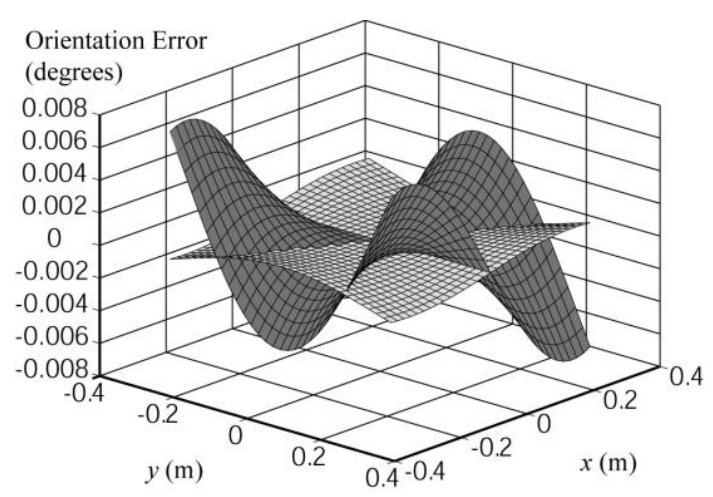

(f) Errors caused by the rotation of the platform about the $\mathbf{Z}$ axis.

Fig. 11. Errors caused by the linear displacements and the rotation of the platform due to the elasticity of links for unbalanced (dark gray) and balanced (light gray) Delta robot calculated for the altitude $z=-1 \mathrm{~m}$.

\section{Prototype and experimental validation}

\subsection{Prototype}

A prototype has been designed and built for validation of the obtained results. It was implemented in the structure of the Delta robot of the SurgiScope ${ }^{\circledR}$ provided by the I.S.I.S Company. To design the prototype, the first stage is to find the optimal lengths of the multiloop pantograph linkage taking into account that it should not collide with the legs of the 
Delta robot. Then the appropriate stiffness characteristics of the multiloop pantograph linkage were found by evolution of the shapes and design concept of links, as well as by successive optimization based on the finite element analysis.
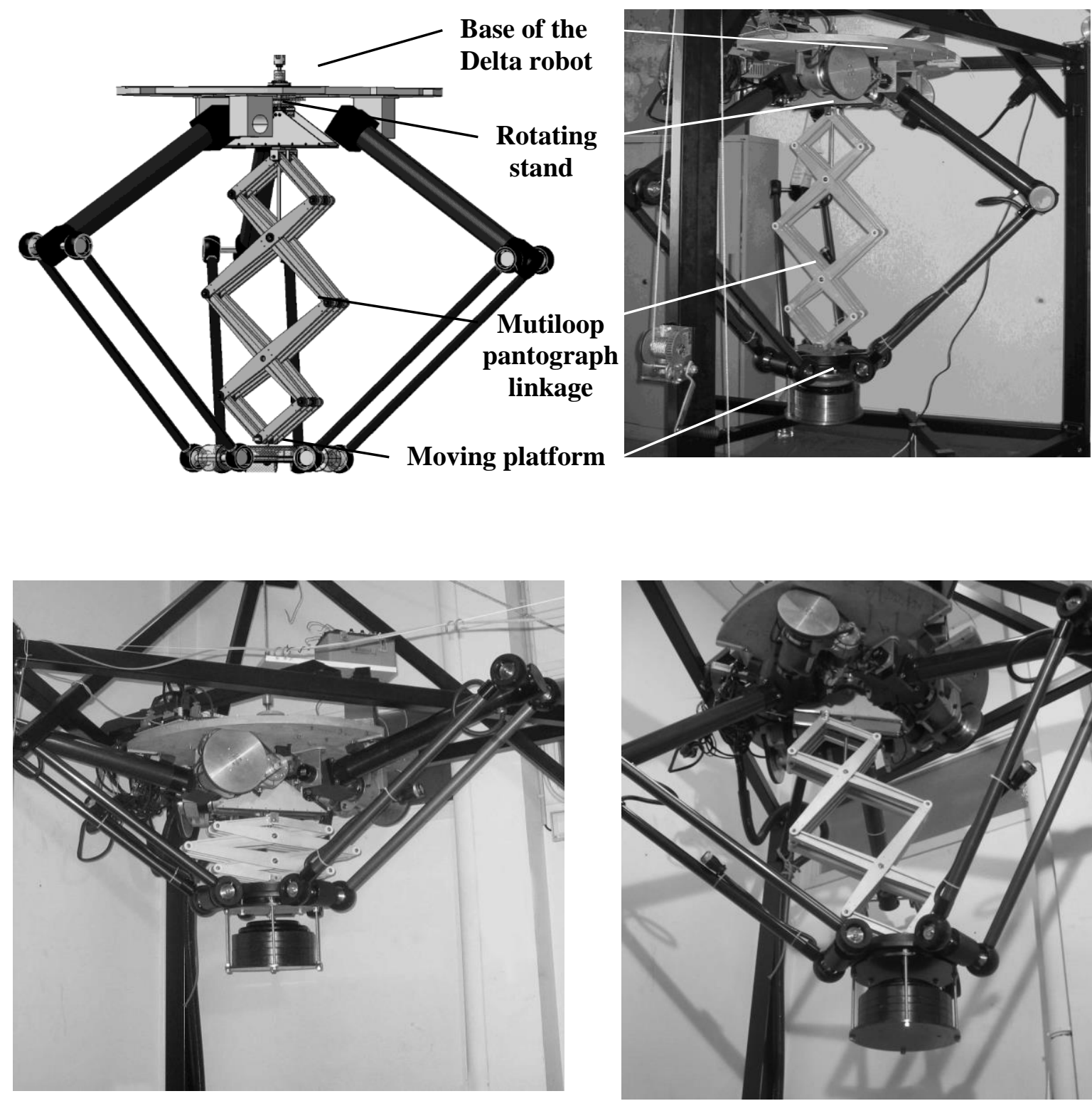

Fig. 12. CAD model and prototype of the balancing mechanism implemented in the structure of the Delta robot.

After assembling the prototype, its static balance was verified by placing it vertically and noting that the mechanism is in equilibrium in any of its configurations. In such a manner, the 
balancing force for developed multiloop pantograph linkage was found through experimentation $\left(F_{\mathrm{B} / \text { PANTOGRAPH }}=52 \mathrm{~N}\right)$. The base of the balancing mechanism was then suspended from the fixed structure of the Delta robot and its end was connected to the moving platform (Fig. 12). In order to create a balancing force, a counterweight was used. It is obvious that for industrial applications it is better to use pneumatic cylinders or electric actuators with constant moment. However, the validation of the obtained results can also be achieved by a counterweight, which develops the same force as a pneumatic cylinder or electric actuator.

\subsection{Experimental bench}

The experimental bench (Fig. 13) is composed of the Delta robot with its control system, a computer to interact with the user and a dSPACE 1103 board. The sampling period is $1 \mathrm{~ms}$ (corresponding sampling frequency $f_{e}$ ).

The Delta Robot is composed of three Parvex RX320E DC servo motors with the following main characteristics:

- rated speed: $3000 \mathrm{tr} / \mathrm{min}$ and maximum speed: $3900 \mathrm{tr} / \mathrm{min}$;

- rated torque (in slow rotation) : $1.08 \mathrm{Nm}$;

- rated current: $7.8 \mathrm{~A}$ and instantaneous maximum current: $20 \mathrm{~A}$;

- 100000 encoder pulses per revolution (resolution: 0.0036 degree). 


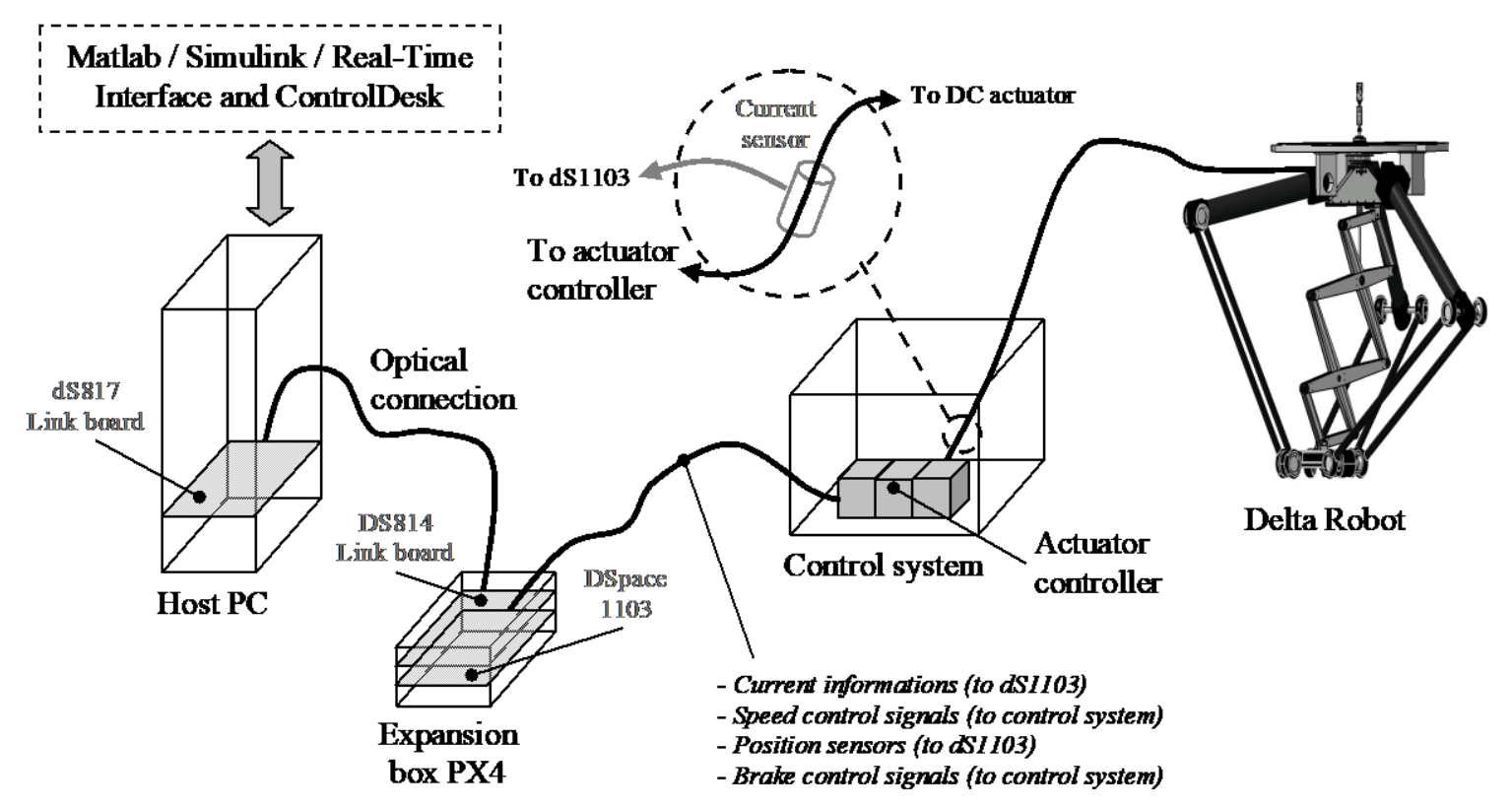

Fig. 13. Experimental bench.

To show the improvement made in an industrial system by the balancing mechanism, we have preserved the existing industrial control system and used its speed control entries to actuate the motors. The dSPACE 1103 realizes the interface between the PC and the servosystem. This board allows the control of our 3 motorized axes and has specific entries to which we have directly connected our 3 incremental encoders. To control the system the software Matlab/Simulink/RTI/ControlDesk have been used.

The robot is controlled by a classical PID law, already included in the industrial control system. We have observed the torque response of the system to a movement composed of a straight line with respect to $\mathbf{Z}$ axis and a circle in the space (Fig. 14). 


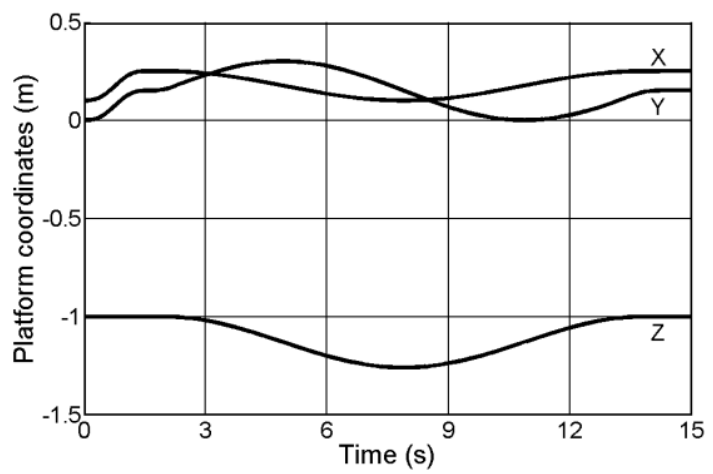

Fig. 14. Selected trajectory for experimental validation of torque minimization.

\subsection{Experimental results and comparative analysis}

The input torques measured for each actuator in different cases are denoted by A, B, C and D:

A. unloaded robot;

B. loaded robot (robot with the load of $690 \mathrm{~N}$ );

C. load balanced robot (balancing by mechanism with force of $690 \mathrm{~N}$ );

D. load and mechanical system balanced robot (balancing by mechanism with force of $880 \mathrm{~N})$.

We would like to draw attention to cases $\mathrm{C}$ and $\mathrm{D}$. In case $\mathrm{C}$, we have only compensated the load added on the robot platform, to obtain the same result as thus obtained when the robot is unloaded. In case D, we have taken into account the mass of the Delta Robot links, which gives the best result.

The measured input torques have been taken for two different speeds of the movement (maximal cartesian acceleration and maximal cartesian speed):

Experiment 1 (E1): $15 \%$ of the maximum capacity of the robot to neglect most of the dynamic effects (we consider it as the static mode of operation).

Experiment 2 (E2): $100 \%$ of the maximum capacity of the robot to observe the improvement for dynamic mode of operation. 


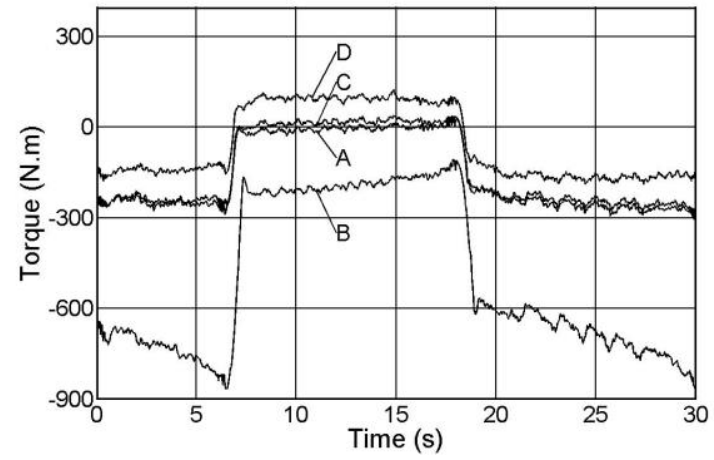

(1a) Input torque 1 (case E1)

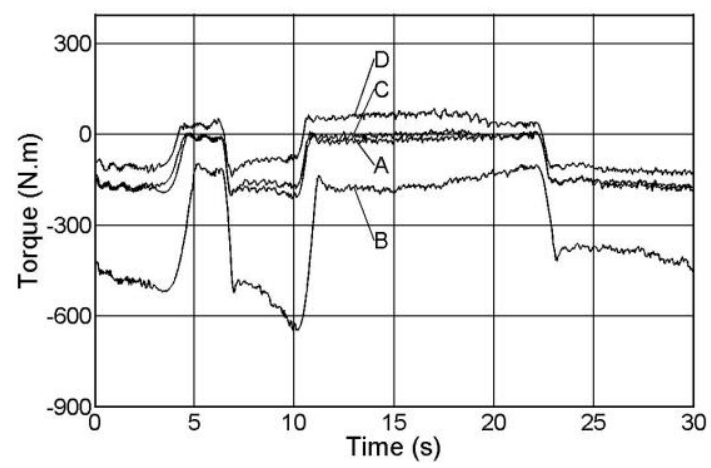

(2a) Input torque 2 (case E1)

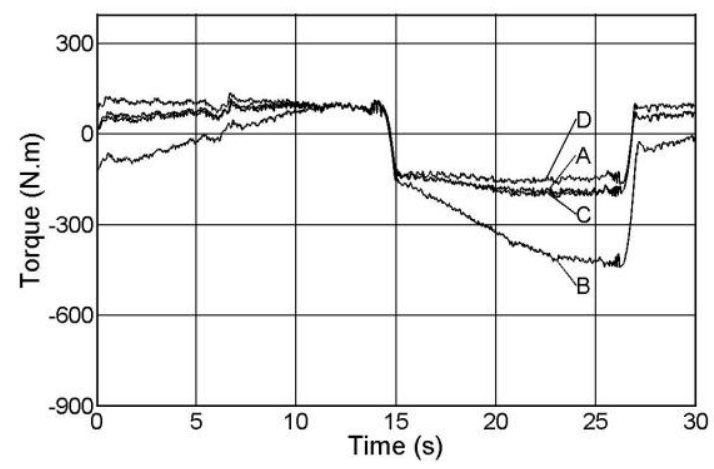

(3a) Input torque 3 (case E1)

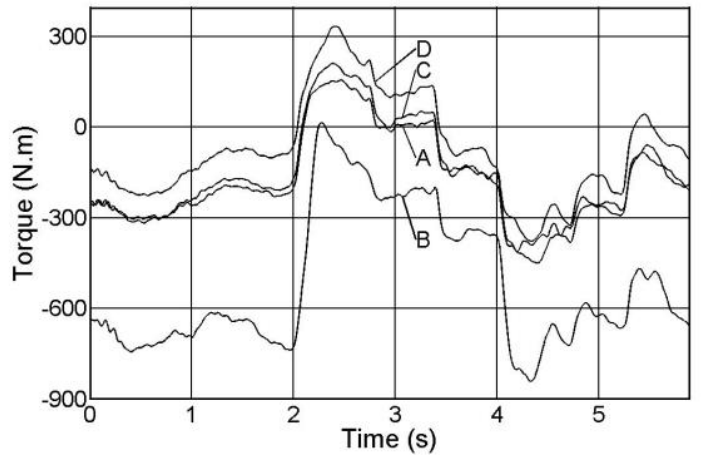

(1b) Input torque 1 (case E2)

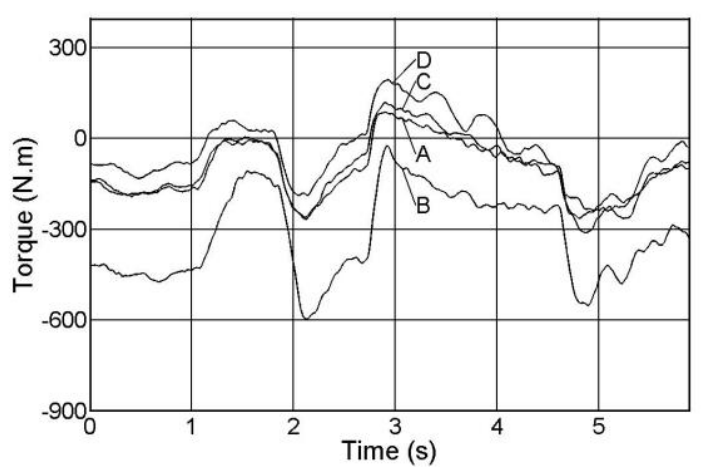

(2b) Input torque 2 (case E2)

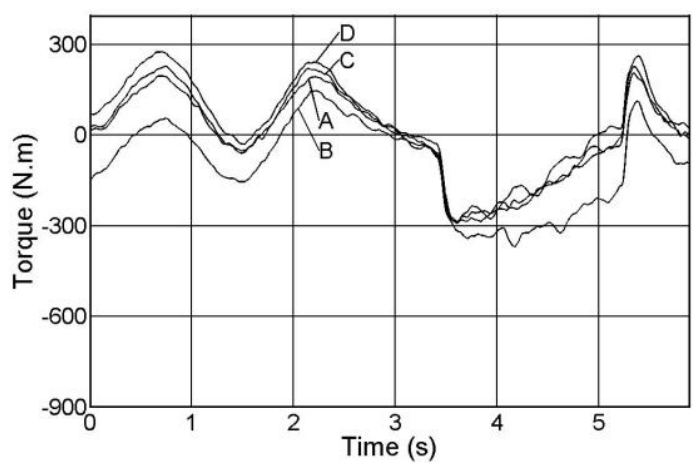

(3b) Input torque 3 (case E2)

Fig. 15. Experimental measures of input torques for three actuators of the Delta robot.

The obtained measurements confirm perfectly the theoretical results (Fig. 15):

- When balancing is carried out by taking into account only the load on the platform, the results are similar to those obtained for the unloaded robot (cases A and C). 
- When balancing is carried out by taking into account the load on the platform and loads of robot links, we obtain the lowest values for the input torques (cases D).

Tables 6 and 7 show the reduction of the input torques for experiments 1 (E1) and 2 (E2).

Table 6. Input torques (E1: static mode of operation)

\begin{tabular}{|c|c|c|c|c|c|c|c|}
\hline & & \multirow{2}{*}{ A } & \multirow{2}{*}{ B } & \multirow{2}{*}{$\mathrm{C}$} & \multirow{2}{*}{$\mathrm{D}$} & \multicolumn{2}{|c|}{ Improvement gain ${ }^{3}(\%)$} \\
\hline & & & & & & $\mathrm{C}$ & $\mathrm{D}$ \\
\hline \multirow{3}{*}{$\begin{array}{c}\text { Maximum } \\
\text { values of the }\end{array}$} & Actuator 1 & 306 & 882 & 324 & 199 & 63 & 77 \\
\hline & Actuator 2 & 217 & 653 & 208 & 145 & 68 & 77 \\
\hline & Actuator 3 & 211 & 449 & 221 & 180 & 50 & 59 \\
\hline
\end{tabular}

Table 7. Input torques (E2: dynamic mode of operation)

\begin{tabular}{|c|c|c|c|c|c|c|c|}
\hline & & \multirow{2}{*}{ A } & \multirow{2}{*}{ B } & \multirow{2}{*}{$\mathrm{C}$} & \multirow{2}{*}{$\mathrm{D}$} & \multicolumn{2}{|c|}{ Improvement gain ${ }^{3}(\%)$} \\
\hline & & & & & & $\mathrm{C}$ & $\mathrm{D}$ \\
\hline \multirow{2}{*}{$\begin{array}{l}\text { Maximum } \\
\text { values of the }\end{array}$} & Actuator 1 & 456 & 880 & 502 & 423 & 43 & 52 \\
\hline & Actuator 2 & 291 & 608 & 342 & 264 & 44 & 56 \\
\hline measured & Actuator 3 & 313 & 400 & 320 & 328 & 20 & 18 \\
\hline
\end{tabular}

We can observe that improvement for actuators 1 and 2 in the quasi static movement is $77 \%$ and for actuator 3 is $59 \%$. For the dynamic mode of operation the improvement for actuator 1 is $52 \%$, for actuator 2 is $56 \%$ and for actuator 3 is $18 \%$.

\footnotetext{
${ }^{3}$ This gain represents in percent the reduction of the torques compared to (-) case B.
} 
Gains for actuator 3 are quite different from the two others, because this one was less solicited by the given trajectory than the two others, i.e. for the given trajectory the load of the platform on actuator 3 was smaller (see Table 7, case B). So, it is natural that for this actuator we do not observe consequent improvement of its torque by the balancing mechanism.

The experimental validation of the suggested balancing approach showed that satisfactory results are achieved and the developed system is fully operational.

Table 8. Trajectory for experimental validation of the positioning accuracy improvement.

\begin{tabular}{|c|c|c|c|}
\hline Points & $x(\mathrm{~mm})$ & $y(\mathrm{~mm})$ & $z(\mathrm{~mm})$ \\
\hline 1 & 400.0 & 0.0 & -900.0 \\
\hline 2 & 325.5 & 41.7 & -949.9 \\
\hline 3 & 249.9 & 84.4 & -1000.2 \\
\hline 4 & 175.6 & 127.5 & -1050.0 \\
\hline 5 & 100.3 & 169.9 & -1100.1 \\
\hline 6 & 25.5 & 212.4 & -1199.7 \\
\hline 7 & -49.9 & 255.4 & -1249.6 \\
\hline 8 & -124.8 & 298.3 & -1299.8 \\
\hline 9 & -200.8 & 340.7 & \\
\hline
\end{tabular}

The next step of the experimental validation is the estimation of the positioning errors for balanced and unbalanced robots. For this purpose a trajectory given by the following 9 points was chosen (table 8).

These points are uniformly distributed about a straight line of $800 \mathrm{~mm}$ length. To obtain this line physically, a sphere is used, which was moved along a rail (Fig. 16). The position of each point is measured by three dial gauges, which determine the center of the sphere. The 
purpose of these measurements is to obtain the positioning errors for unbalanced and balanced Delta robots.

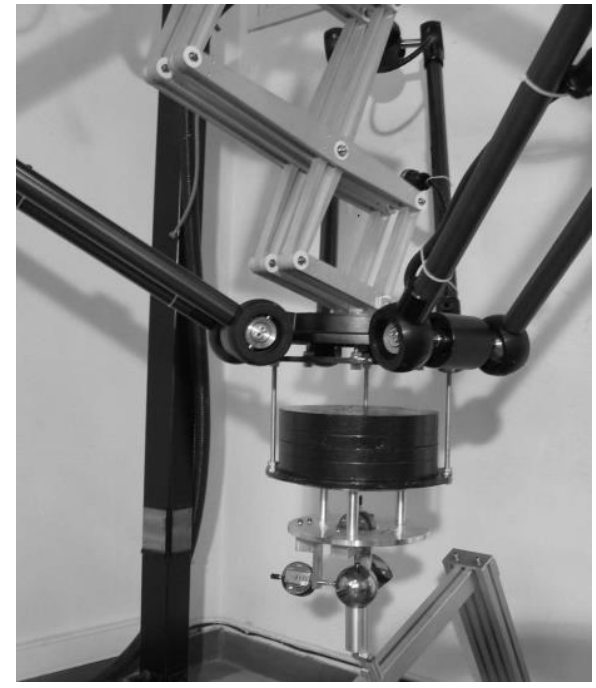

Fig. 16. Measuring of the positioning errors for given straight line trajectory.

The obtained results are shown in Fig. 17. The abscissa axis corresponds to the unloaded case. Then the Delta robot was loaded and the relative errors were measured (graph "unbalanced robot"). Finally the robot was balanced by the suggested mechanism and relative errors are shown for the "balanced robot". The average rate of the improvement in the relative positioning accuracy with respect to $\mathbf{Z}$ axis is $93.5 \%$, which corresponds to the value obtained by the numerical simulations.

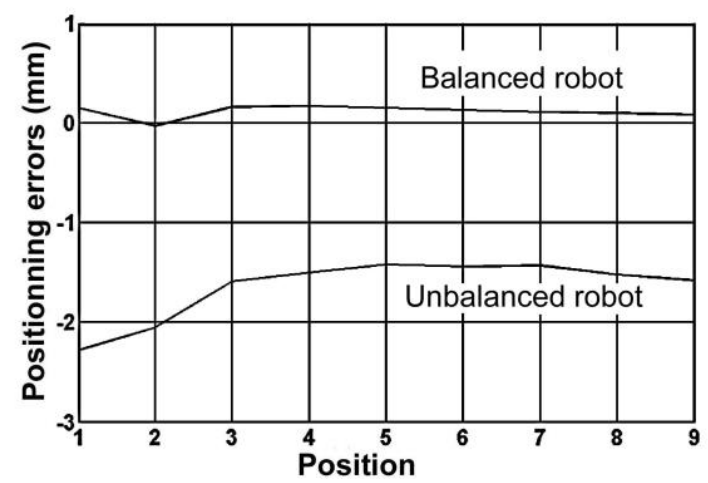

Fig. 17. Relative positioning errors with respect to $z$ axis for unbalanced and balanced robots. 
With regard to the measurement of other positioning and orientation errors, caused by the displacement of the platform, we observed that the frame of the robot is insufficiently rigid in a cross-section direction. Taking into account the important mass of the counterweight, it is strongly deformed and leads to significant distortions of the measured parameters.

\section{Conclusion}

In this paper, a new approach for balancing of spatial parallel manipulators has been presented. It involves connecting a secondary mechanical system to the initial robot, which generates a vertical force applied to the platform of the manipulator. The suggested balancing mechanism is designed on the base of the multiloop pantograph linkage introduced between the robot base and the platform. The minimization of the input torques was carried out by constant and variable forces for static and dynamic modes of operation. It was shown that a significant reduction in input torques can be achieved by the suggested balancing mechanism: the reduction of the root-mean-square value of the input torque due to the gravitational forces is $99.5 \%$ and the maximum value is $92 \%$. The positioning errors of the unbalanced and balanced parallel manipulators are provided. It was shown that the elastic deformations of the manipulator structure due to the payload, change the altitude and the inclination of the platform. A significant reduction in these errors is achieved by using the balancing mechanism (from $86.8 \%$ to $97.5 \%$ ). The theoretical results obtained by numerical simulations were confirmed by experimental study carried out by means of the developed prototype mounted on the Delta robot.

It should be noted that the suggested balancing mechanism not only improves the positioning accuracy of the parallel robot, but also sharply reduces stress in its links and efforts in the joints. This system can also be used for operational safety of robotized medical 
devices because it can maintain the fixed position of the platform if the parallel robot actuators should accidentally stop.

The suggested balancing approach was demonstrated for the Delta robot but the designed mechanism can be applied to many spatial parallel robots with 3 to 6 degrees of freedom. This type of mechanism is expected to lead to designs that can carry a larger payload and/or reduce energy consumption.

Finally, it should be noted that the proposed balancing mechanism has been patented [44] and additional information is available upon request.

\section{Acknowledgments}

The authors would like to thank the «Intelligent Surgical Instruments and Systems» Company for its financial support and Professor Jean Le Flecher for the advice during development of the prototype.

\section{References}

[1] Lowen G. G., Tepper F. R., Berkof R. S., 1983, "Balancing of Linkages - Update". Mechanism and Machine Theory, Vol. 18 (3), pp.213-230.

[2] Arakelian, V. and Smith, M.R., 2005, "Shaking force and shaking moment balancing of mechanisms: an historical review with new examples,” J. Mech. Design Trans. ASME, Vol. 127, March, pp. 334-339 (see also ERRATUM, Vol. 127, September 2005, pp. 1034-1035) (2005).

[3] Agrawal, S.K. and Fattah, A., 2004, "Reactionless space and ground robots: novel designs and concept studies," Mechanism and Machine Theory, Vol. 39, pp. 25-40.

[4] Wang, J. and Gosselin, C.M., 1999, "Static balancing of spatial three-degree-of-freedom parallel mechanisms,” Mechanism and Machine Theory, Vol. 34, pp. 437-452. 
[5] Newman, W.S. and Hogan, N., 1986, "The optimal control of balanced manipulators," Proc. winter annual meeting of the ASME, Anaheim, California.

[6] Laliberté, T., Gosselin, C.M. and Jean, M., 1999, "Static balancing of 3-DOF planar parallel mechanisms," IEEE/ASME Transactions on Mechatronics, Vol. 4, No. 4, December, pp. 363-377.

[7] Fujikoshi, K., 1976, "Balancing apparatus for jointed robot," Patent JP51-122254, October 26.

[8] Arakelian, V., 1989, “Manipulator”, Patent SU 1465298, March 15.

[9] Wang, J. and Gosselin, C.M., 2000, "Static balancing of spatial four-degree-of-freedom parallel mechanisms,” Mechanism and Machine Theory, Vol. 35, pp. 563-592.

[10] Russo, A., Sinatra, R. and Xi, F., 2005, "Static balancing of parallel robots," Mechanism and Machine Theory, Vol. 40, pp. 191-202.

[11] Lakota, N.A. and Petrov, L.N., 1985, "Manipulators for assembly tasks." In the book “Automation of assembly tasks", Moscow, pp.137-153.

[12] Ebert-Uphoff, I., Gosselin, C.M. and Laliberté, T., 2000, "Static balancing of spatial parallel mechanisms - Revisited.” J. Mech. Design Trans. ASME, Vol. 122, pp. 43-51.

[13] Herder, J.L., 2001, "Energy-free systems. Theory, conception and design of statically balanced mechanisms", Ph.D. thesis, Delf University of Technology.

[14] Streit, D.A. and Shin, E., 1993, "Equilibrators for planar linkages," J. Mech. Design Trans. ASME, Vol. 115, pp. 604-611.

[15] Vrijlandt, N. and Herder, J.L., 2002, "Seating unit for supporting a body or part of a body”, Patent NL1018178, December 3.

[16] Vladov, I.L., Danilevskij, V.N. and Rassadkin, V.D., 1981, "Module of linear motion of industrial robot”, Patent SU 848350, July 23. 
[17] Ebert-Uphoff, I. and Johnson, K., 2002, "Practical considerations for the static balancing of mechanisms of parallel architecture", Journal of Multi-body Dynamics, Vol. 216, Part K, pp.73-85.

[18] Tuda, G. and Mizuguchi, O., 1983, “Arm with gravity-balancing function”, Patent US4383455, May 17.

[19] Herder, J.L., 2002, "Some considerations regarding statically balanced parallel mechanisms," Proc. WORKSHOP on Fundamental Issues and Future Research Directions for Parallel Mechanisms and Manipulators”, Quebec City, Quebec, Canada, October 3-4.

[20] Leblond, M. and Gosselin, C.M., 1998, "Static balancing of spatial and planar parallel manipulators with prismatic actuators”, Proc. DETC'98, Atlanta, Georgia , USA, pp.112.

[21] Popov, M. and Tyurin, V., 1988, "Balanced manipulator", Patent SU 1379105, March 7.

[22] Agrawal, A. and Agrawal, S.K., 2005, "Design of gravity balancing leg orthosis using non-zero free length springs,” Mechanism and Machine Theory, Vol. 40, pp. 693-709.

[23] Simionescu, I. and Ciupitu, L., 2000, "The static balancing of the industrial arms. Part I: Discrete balancing”, Mechanism and Machine Theory, Vol. 35, pp. 1287-1298.

[24] Segla, S, Kalker-Kalkman, C.M. and Schwab, A.L., 1998, "Statical balancing of a robot mechanism with the aid of a genetic algorithm," Mechanism and Machine Theory, Vol. 33, No. 2, pp. 163-174.

[25] Minotti, P. and Pracht, P., 1988, "Ressort et mécanismes : une solution aux problèmes d'équilibrage", Mechanism and Machine Theory, Vol. 23, pp. 157-168.

[26] Dzhavakhyan, R.P. and Dzhavakhyan, N.P., 1989, "Balanced manipulator", Patent SU1521579, November 15.

[27] Hervé, J., 1985, "Device for counter-balancing the forces due to gravity in a robot arm", Patent FR2565153, June 12. 
[28] Bartlett, D.S., Freed, D.I. and Poynter, W.H., 1988, "Robot with spring pivot balancing mechanism", Patent US4753128, June 28.

[29] Popov, M.V., Tyurin, V.N. and Druyanov, B.A., 1984, "Counterbalanced manipulator" Patent SU1065186, January 7.

[30] Simionescu, I. and Ciupitu, L., 2000, "The static balancing of the industrial arms. Part I: Continuos balancing”, Mechanism and Machine Theory, Vol. 35, pp. 1299-1311.

[31] Lakota, N.A. and Petrov, L.N., 1985, "Manipulators for assembly tasks." In the book “Automation of assembly tasks", Moscow, pp.137-153.

[32] Kondrin, A.T., Petrov, L.N. and Polishchuk, N.F., 1990, "Pivoted arm balancing mechanism" Patent SU1596154, September 30.

[33] Petrov, L.N. and Polishchuk, N.F., 1979, "Vertical displacement device", Patent SU643323, January 25.

[34] Popov, M.V. and Tyurin, V.N., 1983, "Balanced manipulator", Patent SU1000271, February 28.

[35] Gvozdev, Y.F., 1992, “Manipulator”, Patent SU1777993, October 30.

[36] Gvozdev, Y.F., 1990, “Manipulator”, Patent SU1537512, January 23.

[37] Gvozdev, Y.F., 1987, “Manipulator”, Patent SU1308463, May 7.

[38] Belyanin, P.N., 1988, "Balanced manipulators," Mashinostroynie, Moscow, 263p.

[39] Wildenberg, F., 2002, “Compensating System for a Hexapod”, Patent US6474915, November 5.

[40] Dzhavakhyan, R.P. and Dzhavakhyan, N.P., 1987, "Balanced manipulator", Patent SU1357218, December 7.

[41] Segawa, Y., Yamamoto, M. and Shimada, A., 2000, "Parallel Link Mechanism”, Patent JP2000120824, April 28.

[42] Clavel, R., 1990, "Device for movement and displacing of an element in space," Patent US4976582, December 11. 
[43] Miller, K. and Clavel, R., 1992, "The Lagrange-based model of Delta-4 robot dynamics," Robotersysteme, Vol. 8, pp.49-54.

[44] Baradat, C., Arakelian, V. and Maurine, P., 2006, "Parallel robot including of loadcompensation system," Patent FR2880575, July 14. 


\section{List of figures}

Fig. 1. A Delta robot used in the SurgiScope ${ }^{\circledR}$, a robotized navigation tool-holder designed for neurosurgery and developed by the ISIS company.

Fig. 2. Principle of balancing.

Fig. 3. Simplified scheme of the balancing mechanism.

Fig. 4. Delta robot with the balancing mechanism.

Fig. 5. Stewart platform with implemented balancing system.

Fig. 6. Gravitational forces for the leg $i$.

Fig. 7. Input torque 1 for unbalanced (left) and balanced (right) Delta robot.

Fig. 8. The output parameters for the selected trajectory.

Fig. 9. Input torque 1 for unbalanced and balanced Delta robot.

Fig. 10. Input torque 1 for unbalanced and balanced Delta robot.

Fig. 11. Errors caused by the linear displacements and the rotation of the platform due to the elasticity of links for unbalanced (dark gray) and balanced (light gray) Delta robot calculated for the altitude $z=-1 \mathrm{~m}$.

Fig. 12. CAD model and prototype of the balancing mechanism implemented in the structure of the Delta robot.

Fig. 13. Experimental bench.

Fig. 14. Selected trajectory for experimental validation of torque minimization.

Fig. 15. Experimental measures of input torques for three actuators of the Delta robot.

Fig. 16. Measuring of the positioning errors for given straight line trajectory.

Fig. 17. Relative positioning errors with respect to $z$ axis for unbalanced and balanced robots. 


\section{List of tables}

Table 1. Balancing schemes for robotic systems

Table 2. Input torques for unbalanced and balanced robots

Table 3. Input torques for unbalanced and balanced robots

Table 4. Link parameters

Table 5. Maximal absolute positioning and orientation errors for unbalanced and balanced robots

Table 6. Input torques (E1: static mode of operation)

Table 7. Input torques (E2: dynamic mode of operation)

Table 8. Trajectory for experimental validation of the positioning accuracy improvement. 